\title{
Anterior segment dysgenesis in mosaic Turner syndrome
}

\author{
I C Lloyd, P M Haigh, J Clayton-Smith, P Clayton, D A Price, A E A Ridgway, D Donnai
}

\begin{abstract}
Aims/background-Females with Turner syndrome commonly exhibit ophthalmological abnormalities, although there is little information in the literature documenting findings specific to Turner syndrome mosaics. Ophthalmic findings are described in four patients with mosaic Turner syndrome. All had anterior chamber abnormalities and all four had karyotypic abnormalities with a $45, \mathrm{X}$ cell line. The possible relation between the karyotypic and the phenotypic findings in these patients is discussed.

Methods-Four girls with mosaic Turner syndrome underwent a full ophthalmological assessment, including examination under anaesthesia where indicated.

Results-Three of the four patients presented with congenital glaucoma. Two had the karyotype $45, X / 46, X, \operatorname{idic}(Y)$ and one a 45, X/47, XXX karyotype. The remaining child had a Rieger malformation of the iris and the karyotype $45, X / 46, X, r(X)$.

Conclusions-These findings suggest that Turner syndrome mosaicism (where there are two abnormal cell lines) is associated with anterior segment dysgenesis. The findings in these four patients are compared with those seen in other mosaic phenotypes and it is postulated that the presence of two or more genetically different cell lines may have an adverse effect on anterior segment development.

(Br F Ophthalmol 1997;81:639-643)
\end{abstract}

Manchester Royal Eye

Hospital

I C Lloyd

P M Haigh

A E A Ridgway

Regional Genetics Service, St Mary's Hospital, Manchester

J Clayton-Smith

D Donnai

Department of Child Health, Growth Clinic, St Mary's Hospital, Manchester

P Clayton

D A Price

Correspondence to: Mr I C Lloyd, Manchester Royal Eye Hospital, Oxford Road, Manchester M13 9WH.

Accepted for publication 10 April 1997
Materials and methods
The clinical details of four patients seen both in the paediatric ophthalmology clinic and in the department of clinical genetics are presented. All patients underwent full general and ophthalmic examination. Three had examination of their eyes under anaesthesia. A detailed chromosome analysis was carried out on each of the four patients.

\section{Results}

CASE 1

This child was born at term weighing $2.5 \mathrm{~kg}$. At 2 months of age her parents noted that she had watering, photophobic eyes, and that her left eye appeared larger than her right (Fig 1A). Ophthalmic examination revealed the left cornea to be cloudy and oedematous with splits in Descemet's membrane (Fig 1B). At subsequent examination under anaesthesia corneal diameters of $11 \mathrm{~mm}$ on the right and $12.5 \mathrm{~mm}$ on the left were found, with raised intraocular pressure (IOP) in the left eye. Gonioscopy demonstrated bilateral iris hypoplasia with trabeculodysgenesis in the left eye, but no significant optic disc cupping. A nasal goniotomy was performed on the left eye. The IOP initially fell but by 9 weeks postoperatively it had risen again (to $18 \mathrm{~mm} \mathrm{Hg}$ ) with a corresponding increase in corneal diameter to $13 \mathrm{~mm}$. A temporal goniotomy was therefore performed. Subsequently the IOP remained controlled and the cornea cleared. The child also exhibited marked anisometropia $(-0.50 /+$ 1.00 axis 90 right, $-9.50 \mathrm{DS}$ left) and left esotropia.

She was referred on to a paediatrician because of failure to thrive. Routine investigations carried out at that time revealed that her karyotype was $45, \mathrm{X} / 46, \mathrm{X}, \operatorname{idic}(\mathrm{Y})$ (Fig 1C), with $22 / 30$ cells containing an isodicentric $Y$ chromosome. This karyotype is consistent with Turner syndrome mosaicism. Her growth and hormonal status are currently being monitored and gonadectomy has been discussed, because of the significant risk of malignancy developing in her dysgenetic gonads in the presence of $\mathrm{Y}$ chromosome material. At 12 months of age forced choice preferential looking tests indicated visual acuities of 20/100 on the right and $20 / 400$ on the left. A daily wear soft contact lens was fitted to the left eye and occlusion therapy of the right eye commenced. Subsequently her left eye myopia has reduced to -4.50 DS. Currently, visual acuity is $6 / 6$ right, $6 / 12$ left (Cardiff acuity cards), the left IOP is $16 \mathrm{~mm} \mathrm{Hg}$, both optic discs appear normal and her esotropia is stable. Her growth continues parallel to the 3 rd centile (50th centile for Turner syndrome) without growth hormone 

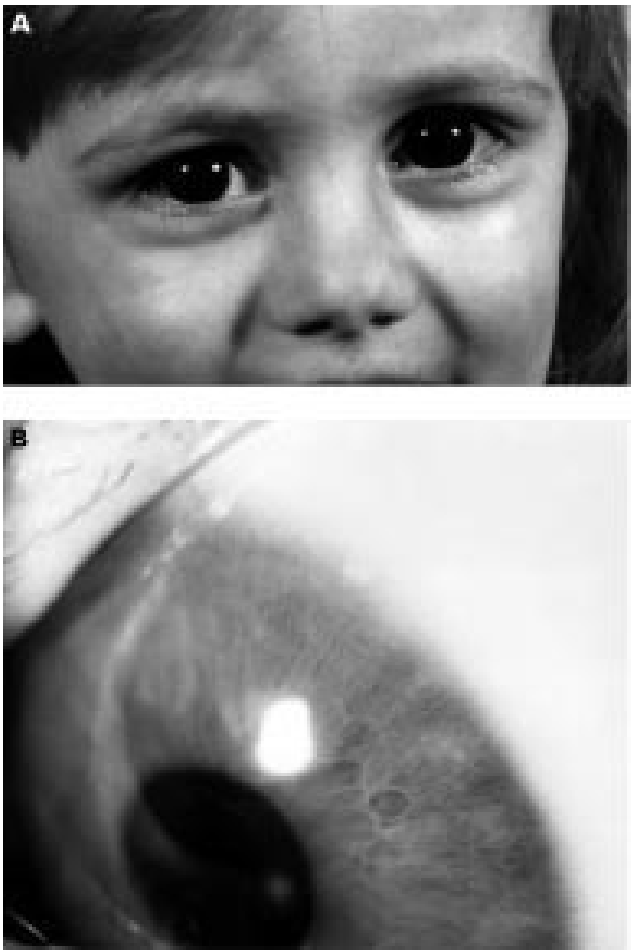

Figure 1 Case 1. (A) Left corneal enlargement. (B) Splits in Descemet's membrane of the left cornea. (C) Karyotype of the abnormal cell line, 46, $X$, idic (Y). Arrows on the karyotype indicate the $X$ and isodicentric (Y) chromosomes.

replacement and her development is within normal limits.

CASE 2

This child was born at term weighing $2.9 \mathrm{~kg}$. Her parents were concerned about her vision from the age of 6 weeks noting her watering eyes and photophobia. At 5 months of age she presented to the paediatric department with an additional symptom of excessive drowsiness and was investigated for a possible viral infection. She was referred on for an ophthalmic opinion. On examination both corneas were enlarged (Fig 2A) and cloudy. Examination under anaesthesia revealed corneal diameters of $13.5 \mathrm{~mm}$, corneal oedema, and splits in Descemet's membrane bilaterally. The IOPs were $24 \mathrm{~mm} \mathrm{Hg}$ on the right and $20 \mathrm{~mm} \mathrm{Hg}$ on the left. A right inferior goniotomy and a left upper temporal quadrant trabeculotomy were performed. Examination under anaesthesia 2 weeks later showed persistence of raised right IOP and a nasal goniotomy was performed. Subsequently IOPs have remained controlled and the optic discs appear normal.

A routine chromosome analysis showed that $50 \%$ cells had a $45, \mathrm{X}$ karyotype and $50 \%$ were 46, X, idic(Y) (Fig 2B). At 9 months, length and weight were on the $3 \mathrm{rd}$ centile and head circumference on the 10th-25th centile. She had no obvious dysmorphic features and a cardiac echo and renal ultrasound scan were both normal. At the age of 12 months she underwent a gonadectomy, the histology report confirming streak gonads. On review at $2 \frac{1}{2}$ years her intellectual development was normal, but she had persistent photophobia. She had a low hypermetropic refractive error and visual acuity was $6 / 9$ right, 6/12 left (Kays pictures).
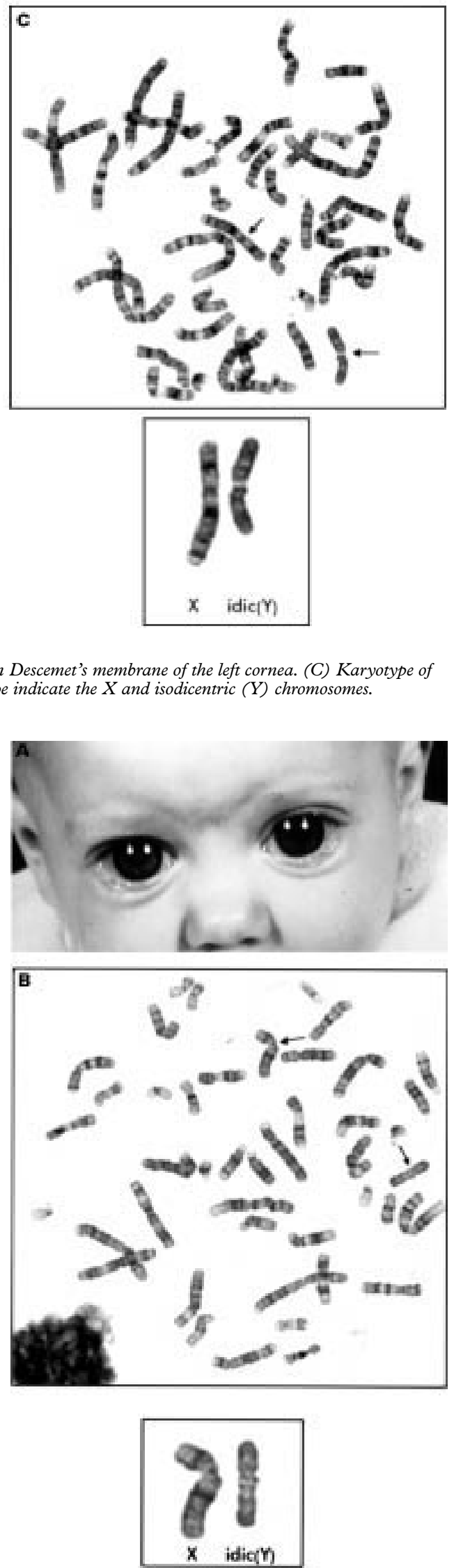

Figure 2 Case 2. (A) Bilateral corneal enlargement. (B) Karyotype of the abnormal cell line, 46, X, idic(Y). Arrows on the karyotype indicate the $X$ and isodicentric (Y) chromosomes. 
Ocular motility was normal and she had good binocular function. Growth hormone treatment was started at age 4 years 2 months.

CASE 3

This child was born at term weighing $2.95 \mathrm{~kg}$ and was noted to have an imperforate anus. Anoplasty was subsequently carried out. She has a brother and a half sister with unexplained developmental delay. Her sister also had duodenal atresia. Chromosome analysis revealed a $45, \mathrm{X} / 47, \mathrm{XXX}$ karyotype (Fig 3A) with $18 / 30$ cells containing $47, \mathrm{XXX}$. She was referred to the genetic clinic where large cloudy corneas were noted. A diagnosis of congenital glaucoma was confirmed in the ophthalmology clinic. Examination under anaesthesia revealed corneal diameters of $14.25 \mathrm{~mm}$ on the right and $14.5 \mathrm{~mm}$ on the left (Fig 3B), with bilateral Descemet's membranes splits. Applanation IOPs were $20 \mathrm{~mm} \mathrm{Hg}$ on the right and $21 \mathrm{~mm} \mathrm{Hg}$ on the left. There was no clear fundal view due to corneal oedema. Bilateral trabeculotomies were performed followed by bilateral inferior goniotomies. Her most recent assessment at the age of 14 months showed IOPs of $10 \mathrm{~mm} \mathrm{Hg}$ on the right and $9 \mathrm{~mm} \mathrm{Hg}$ on the left with corneal diameters of $14 \mathrm{~mm}$ and $14.25 \mathrm{~mm}$ respectively. Both optic discs are deeply cupped. Growth has been entirely normal but she has mild developmental delay. This latter problem may be attributable to the presence of the 47, XXX cell line or could possibly be related to the developmental problems in her siblings. Both of these have been investigated extensively, but no cause has been found for their learning difficulties. Imperforate anus is not a common finding in sex chromosome abnormalities and is unlikely to be related to the karyotype findings in case 3.

CASE 4

This child was born at 37 weeks' gestation weighing $2.3 \mathrm{~kg}$. Her parents noted a squint in early infancy. At 12 months of age she was referred to the paediatric ophthalmology clinic where abnormal irides, suggestive of Rieger anomaly, were noted. She was also found to be small for her age, with height and weight both below the 3rd centile. She had some minor dysmorphic features including down slanting palpebral fissures and prominent ears. Her intellectual development was normal. At 2 years of age a heart murmur was noted and a bicuspid valve was diagnosed on echocardiogram. At 5 years of age endocrine investigations carried out because of poor growth suggested hypergonadotrophic hypogonadism and a chromosome analysis revealed that she had mosaic Turner syndrome with a 45, $\mathrm{X} / 46, \mathrm{X}, \mathrm{r}(\mathrm{X})$ karyotype (Fig 4A).

Ophthalmology review at this time confirmed the presence of iris changes consistent with Rieger malformation (Fig 4B and 4C). Visual acuity was $6 / 9$ with each eye and her corneas were normal. Ocular motility examination showed a small exophoria measuring 8 prism dioptres with good stereoacuity. Follow up has shown her IOPs to lie at the upper end
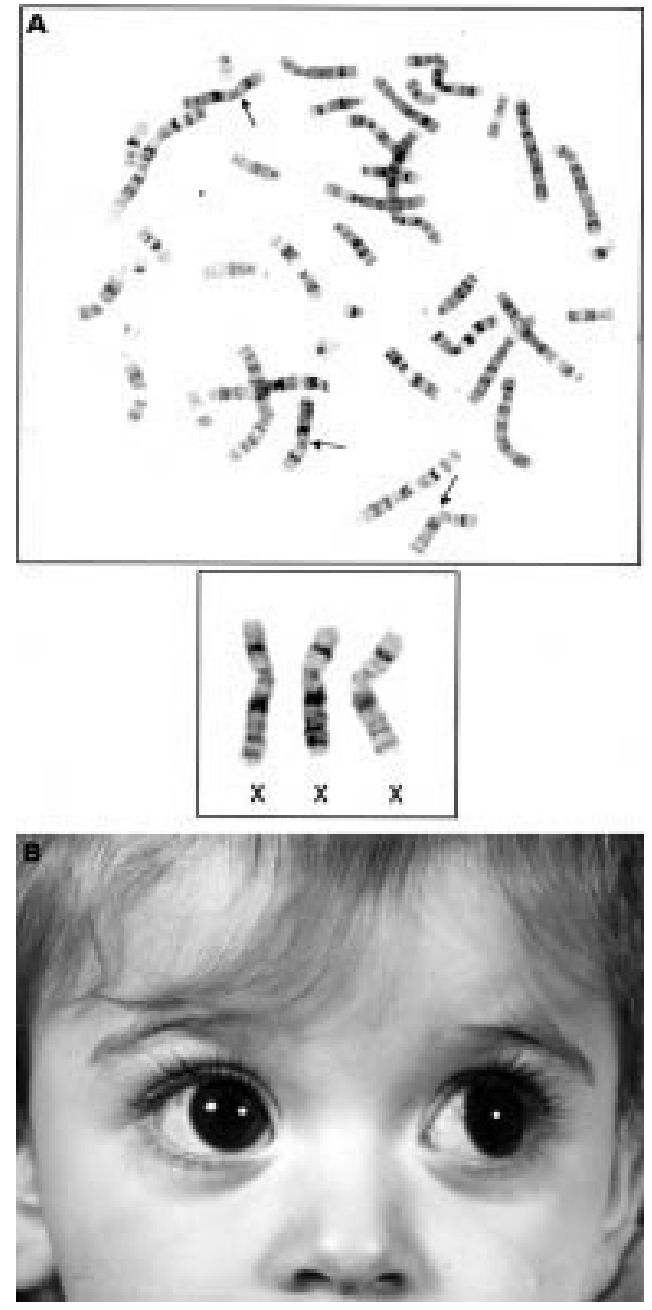

Figure 3 Case 3. (A) Karyotype of the abnormal cell line, 47, XXX. Arrows on the karyotype indicate the three X chromosomes. (B) Bilateral corneal enlargement.

(18-21 mm Hg, pulsair) of the normal range and both optic discs have remained healthy with no significant cupping. Visual acuity, exophoria, and stereoacuity have remained stable. She is currently being treated with growth hormone to which she has shown a moderate early response.

\section{Discussion}

We report four patients with mosaic Turner syndrome and anterior segment dysgenesis. All had a mosaic karyotype with a 45 , $\mathrm{X}$ cell line and a further abnormal cell line. Two patients had a $46, \mathrm{X}, \operatorname{idic}(\mathrm{Y})$ cell line, one a ring $\mathrm{X}$ cell line, and one a 47, XXX cell line. Sex chromosome mosaicism is the commonest type of mosaicism found in humans. The presence of an abnormal cell line at conception is likely to cause mitotic instability giving rise to mosaicism. The presence of two or more cell lines might also suggest chimerism, but this is a much rarer occurrence. ${ }^{10}$

Anterior segment dysgenesis is not a common feature in Turner syndrome although ocular abnormalities, particularly strabismus, are found in $22 \% .{ }^{11}$ The variation in karyotype between the four patients suggests that the anterior segment dysgenesis may not be due to 

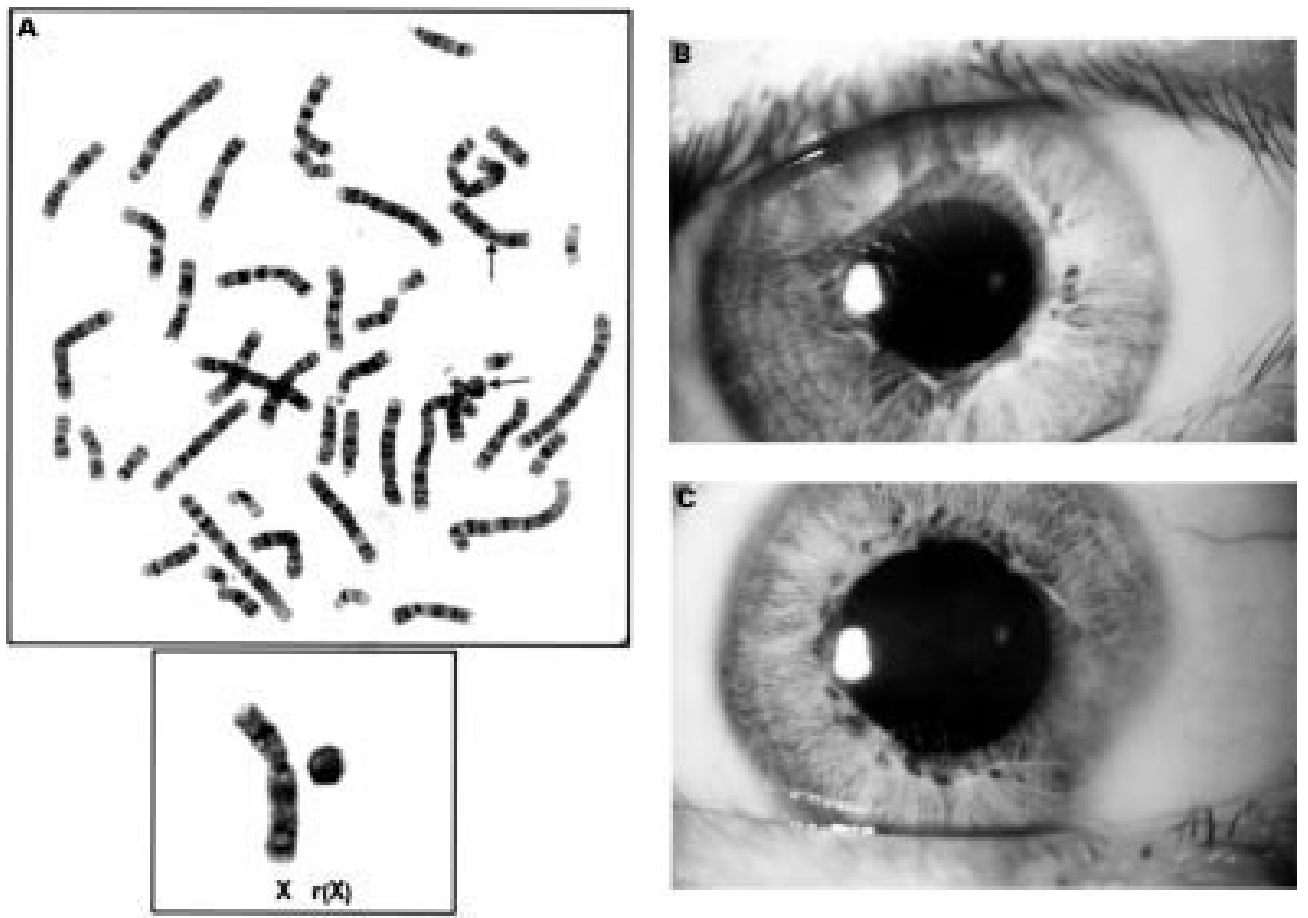

Figure 4 Case 4. (A) Karyotype of the abnormal cell line, 46, $X, r(X)$. Arrows on the karyotype indicate the $X$ and ring (X) chromosomes. Bilateral Rieger malformation. (B) Right eye. (C) Left eye.

the karyotype itself, but may possibly be a phenotypic manifestation of mosaicism. Defects of the anterior segment have been reported previously in association with other mosaic phenotypes such as hypomelanosis of Ito ${ }^{12}{ }^{13}$ and in females affected by $\mathrm{X}$ linked disorders such as Gorlin-Goltz syndrome. ${ }^{14}$ The latter individuals are by definition, functional mosaics as a result of the process of inactivation of one $\mathrm{X}$ chromosome by lyonisation. ${ }^{15}$ In the human female, one of the two X chromosomes is randomly inactivated in early embryonic life and becomes visible as the sex chromatin or 'Barr body' under the nuclear membrane. The descendants of each cell retain the same $\mathrm{X}$ chromosome with either the maternal or the paternal cell being active. A female who has an $\mathrm{X}$ linked trait will be a mosaic with two populations of cells, one with the normal $\mathrm{X}$ and one with the 'abnormal' $\mathrm{X}$ functioning.

It has been proposed that the anterior segment of the eye develops from mesenchyme of neural crest origin which migrates centrally from the rim of the optic cup, and that disorders such as Axenfeld anomaly, Rieger anomaly, and Peter's anomaly arise as a result of defective migration of neural crest cells. The neural crest also plays a part in the pigmentation of the hair, iris, choroid, and skin. Neural crest cells in the skin migrate along the lines of Blaschko which run circumferentially around the trunk and longitudinally down the limbs. Streaky cutaneous pigmentation following the lines of Blaschko can be demonstrated in several mosaic phenotypes including hypomelanosis of Ito $^{16}$ and incontinentia pigmenti. ${ }^{17}{ }^{18}$ The hypopigmented areas have a reduced number of melanocytes, thought to be due to defective migration of melanoblasts from the neural crest. We suggest that the pres- ence of two or more differing cell lines could lead to defective neural crest cell migration and thereby to anterior segment dysgenesis in mosaic phenotypes. In general, girls with Turner syndrome mosaicism have a lower incidence of physical problems than those with a 45 , X karyotype in every cell. They may, however, be at higher risk of anterior segment dysgenesis, particularly where both mosaic cell lines are abnormal, and a routine ophthalmic examination is warranted in this group. Conversely, a chromosome analysis is indicated in female patients presenting with anterior segment dysgenesis or congenital glaucoma.

1 Turner HH. A syndrome of infantilism, congenital webbed neck and cubitus valgus. Endocrinology 1938;23:566.

2 Jacobs PA, Browne C, Gregson N, Joyce C, White H. EstiJacobs PA, Browne C, Gregson N, Joyce C, White H. Esti-
mates of the frequency of chromosome abnormalities detectable in unselected newborns using moderate levels of banding. F Med Genet 1992;29:103-8.

3 Cordier TJ, Reny A. Les manifestations ophtalmologiques du syndrome de Turner. Arch Ophtalmol (Paris) 1969;29: 565-74.

4 Lessel S, Forbes AP. Eye signs in Turner's syndrome. Arch Ophthalmol 1966;76:211-3.

5 Wesson ME. Turner's syndrome. Am Orthopt 7 1971;21:506.

6 Troupe JT, Troupe CC. Evaluation of strabismus in Turner's syndrome. Trans IV Int Orthopt Congr 1981:12730 .

7 Chrousos GA, Ross JL, Chrousos G, Chu FC, Kenigsberg $\mathrm{D}$, Cutler G, Jr, et al. Ocular findings in Turner syndrome. Ophthalmology 1984;91:926-8.

8 Masters MC. Eyes and the Turner syndrome: a nationwide survey. Br Orthopt f 1990;46:7-17.

9 Laurent C, Royer J, Noel G. Syndrome de Turner et glaucome congenital. Bull Soc Ophtal Fr 1961;367-9.

10 Robinson A, de la Chapelle A. Sex chromosome abnormalities. In: Rimoin D, Connor JM, Pyeritz RE, eds. Principles and practice of medical genetics. Edinburgh: Churchill Livingstone, 1996:973-97.

11 Gorlin RJ. Classical chromosome disorders. In: Yunis JJ, ed. New chromosome syndromes. New York: Academic Press, 1977:59-117.

12 Flaherty MP, Padilla CD, Sillence DO. Axenfeld anomaly in association with hypomelanosis of Ito. Ophthalmic Paediatr Genet 1991;12:23-30. 
13 Weaver RG, Martin T, Zanolli MD. The ocular changes of incontinentia pigmenti achromians (hypomelanosis of Ito) f Pediatr Ophthalmol Strabismus 1991;28:160-3.

14 Manzi G, Magli A, Pignalosa B, Liguori G. The GorlinGoltz syndrome: case report. Ophthalmologica (Switzerland) 1990;200:104-6.

15 Lyon MF. Epigenetic inheritance in mammals. Trends Genet 1993;9:123-8.
16 Donnai D, Read AP, McKeown C, Andrews T. Hypomelanosis of Ito: a manifestation of mosaicism or chimerism. $\mathcal{F}$ Med Genet $1988,25: 809-18$

7 Thomas IT, Frias JL, Cantu ES, Lafer CZ, Flannery DB, Graham JG. Association of pigmentary anomalies with chromosomal and genetic mosaicism and chimerism. Am $\mathcal{F}$ Hum Genet 1989;45:193-205.

18 Landy SJ, Donnai D. Incontinentia pigmenti (BlochSulzberger syndrome). f Med Genet 1993;30:53-9. 